University of Nebraska - Lincoln

DigitalCommons@University of Nebraska - Lincoln

\title{
Thermal and Mechanical Properties of Compression-Molded pMDI-Reinforced PCL/Gluten Composites
}

\author{
Abdellatif Mohamed \\ USDA-ARS
}

Victoria L. Finkenstadt

USDA-ARS

Sherald H. Gordon

USDA-ARS

Debra E. Palmquist

USDA-ARS

Follow this and additional works at: https://digitalcommons.unl.edu/usdaarsfacpub

Part of the Agricultural Science Commons

Mohamed, Abdellatif; Finkenstadt, Victoria L.; Gordon, Sherald H.; and Palmquist, Debra E., "Thermal and Mechanical Properties of Compression-Molded pMDI-Reinforced PCL/Gluten Composites" (2010). Publications from USDA-ARS / UNL Faculty. 573.

https://digitalcommons.unl.edu/usdaarsfacpub/573

This Article is brought to you for free and open access by the U.S. Department of Agriculture: Agricultural Research Service, Lincoln, Nebraska at DigitalCommons@University of Nebraska - Lincoln. It has been accepted for inclusion in Publications from USDA-ARS / UNL Faculty by an authorized administrator of DigitalCommons@University of Nebraska - Lincoln. 


\title{
Thermal and Mechanical Properties of Compression-Molded pMDI-Reinforced PCL/Gluten Composites
}

\author{
Abdellatif Mohamed, ${ }^{1}$ Victoria L. Finkenstadt, ${ }^{2}$ Sherald H. Gordon, ${ }^{1}$ Debra E. Palmquist ${ }^{3}$ \\ ${ }^{1}$ Cereal Products and Food Science Unit, National Center for Agriculture Utilization Research, USDA-ARS, \\ Peoria, Illinois 61604 \\ ${ }^{2}$ Plant Polymer Research Unit, National Center for Agriculture Utilization Research, USDA-ARS, \\ Peoria, Illinois 61604 \\ ${ }^{3}$ Midwest Area Statistician, National Center for Agriculture Utilization Research, USDA-ARS, \\ Peoria, Illinois 61604
}

Received 20 May 2009; accepted 30 January 2010

DOI 10.1002/app.32260

Published online 30 June 2010 in Wiley InterScience (www.interscience.wiley.com).

\begin{abstract}
Many biopolymers and synthetic polymers composites were developed by different researchers for environmental protection and for cost reduction. One of these composites is polycaprolactone (PCL) and vital wheat gluten or wheat flour composites were prepared and compatibilized with polymeric diphenylmethane diisocyanate (pMDI) by blending and compression-molding. $\mathrm{PCL} / \mathrm{pMDI}$ blend exhibited glass transition $\left(T_{g}\right)$ at $-67^{\circ} \mathrm{C}$ $\left(0.20 \mathrm{~J} / \mathrm{g} /{ }^{\circ} \mathrm{C}\right)$ and vital gluten at $63^{\circ} \mathrm{C}\left(0.45 \mathrm{~J} / \mathrm{g} /{ }^{\circ} \mathrm{C}\right)$, whereas no $T_{g}$ was recorded for wheat flour. Although $T_{g}$ was unmistakable for either PCL or gluten, all composite exhibited one $T_{g}$, which is strong indication of interaction between PCL and the fillers. Several samples amongst the blended or compression-molded composites exhibited no $T_{g}$ signifying another confirmation of interaction. The $\Delta H$ of the endothermic (melting) and the exothermic (crystallization) for PCL was decreased as the percentage of gluten
\end{abstract}

or flour increased, whereas the overall $\Delta H$ was higher for all composites compared to the theoretical value. The presence of pMDI appeared to strengthen the mechanical properties of the composites by mostly interacting with the filler (gluten or flour) and not as much with PCL. The FTIR analysis ruled out covalent interaction between PCL, pMDI, or the fillers but suggested the occurrence of physical interactions. Based on the data presented here and the data published earlier, the presence of pMDI did not change the nature of interaction between PCL and gluten, but it improved the mechanical properties of the composite. () 2010 Wiley Periodicals, Inc. ${ }^{\dagger} \mathrm{J}$ Appl Polym Sci 118: 27782790,2010

Key words: wheat gluten; PCL; compression molding; mechanical properties; DSC; TGA; FTIR; degradation kinetics; pMDI

\section{INTRODUCTION}

Considering the high cost of fossil energy, there is substantial interest in replacing the entire synthetic plastics by biodegradable polymers in many applications. Although agriculture biomaterials are in abundance, their thermo-mechanical properties are a disadvantage for use as substitutes for synthetic polymers. The drawbacks include hydrophilicity, poor binding, and high viscosity. Conversely, polyesters

\footnotetext{
Names are necessary to report factually on available data; however, the USDA neither guarantees nor warrants the standard of the product, and the use of the name by the USDA implies no approval of the product to the exclusion of others that may also be suitable.

Correspondence to: A. Mohamed (a.mohamed@ars.usda. gov).

Journal of Applied Polymer Science, Vol. 118, 2778-2790 (2010) (c) 2010 Wiley Periodicals, Inc. †This article is a US Government work and, as such, is in the public domain in the United State of America.
}

such as PLA or polycaprolactone (PCL) are expensive $(\$ 3-5 / \mathrm{lb})$ relative to polystyrene and polyolefin. ${ }^{1}$

Polymer blends with at least one biodegradable polymer are called bio-blends. Materials blended with biodegradable polymers for economical product development include: natural polymers, other biodegradable polymers, nonbiodegradable synthetic polymers, compatibilizers, ${ }^{2}$ plasticizers, ${ }^{3-5}$ and salts. ${ }^{6}$ Some of the natural polymers that have been blended with biodegradable polymers for new products include starch, ${ }^{7,8}$ lignin, ${ }^{9}$ gluten, ${ }^{10}$ and nonstarch polysaccharides. ${ }^{8,11,12}$

Generally, the product of polymer blending could be one of the followings: blend with higher or lower thermal stability than the components, which could lead to miscibility (interaction) or lack of interaction between the blend components, respectively. A third condition could be a product with thermal stability between the components, which may indicate improvement of the properties of one of the blend components. ${ }^{13}$ The presence of PCL in bio-blend including polystyrene (PS) resulted in destabilization of PS along with other parameters and showed 
partial miscibility between PCL and PS. ${ }^{14}$ In addition, FTIR-PAS results ${ }^{14}$ showed the presence of $n-\pi$ interaction between PCL and PS. Extruded and injection molded vital gluten (VG)/PCL bio-blends showed that degradation activation energy $\left(E_{a}\right)$ increased at higher levels of VG in nitrogen environment. Differential scanning calorimetry (DSC), Thermogravimetric analysis (TGA) data, and Fourier transform infrared (FTIR) analysis indicated a physical nature of the interaction as opposed to a chemical interaction. ${ }^{15}$

The objectives of this work were to create blends using wheat gluten for its viscoelastic properties as a filling material and PCL for its semicrystalline structure as a continuous phase. This project is a continuation of a previous paper, where PCL/gluten blends were prepared using extrusion and injection-molding. Here, blending was done in a Brabender blender and compression molded rather than injection molded. To improve the interfacial interaction, polymeric diphenylmethane diisocyanate (pMDI) was added to the blends, as it has long been used as a cold setting adhesive in the wood industry. This article is focused on the determination of the thermal properties of the blends using DSC and TGA as well as the mechanical properties and molecular interaction using FTIR.

\section{EXPERIMENTAL}

\section{Materials, polymer blend preparation, and compression molding}

PCL and VG were obtained from commercial sources and were used as received. Vital wheat gluten $(75 \%$ protein) and wheat flour were obtained from Midwest Grain Products (Pekin, IL). PCL was obtained from Dow Chemical Co. (Trade name: Tone 787). Hard Red Spring wheat flour (Miller's Choice) was obtained from North Dakota Mill (Grand Forks, ND). The VG and wheat flour were dried in an oven at $40^{\circ} \mathrm{C}$ overnight before use to minimize moisture. MDI (MONDUR $^{\circledR}$ 541) was obtained from Bayer Material Science LLC (Pittsburg, PA). It is a polymeric MDI consisting of $45-55 \%$ pMDI, $35-45 \%$ MDI, and $1-10 \%$ mixed isomers of MDI.

Different ratios of PCL : Gluten or flour blends were prepared, $90: 10 ; 80: 20 ; 70: 30 ; 60: 40$; 50 : 50; and $30: 70$. Neat PCL, gluten, and flour were used as controls with and without pMDI. Samples $(50 \mathrm{~g})$ were blended in a Brabender PlastiCorder PL2000 mixer (C.W. Brabender Instruments, South Hackensack, NJ). The mixing temperature was set at $120^{\circ} \mathrm{C}$, and the mixing bowl was torque calibrated before sample addition. Samples were mixed at $120^{\circ} \mathrm{C}$ for $5 \mathrm{~min}$ at $10 \mathrm{rpm}$, then $2 \%$ MDI was added (For the 100\% PCL and 70/30 level, samples were made with and without added MDI). After addition of MDI, the mixing speed was increased to
$50 \mathrm{rpm}$ for $25 \mathrm{~min}$. After mixing, samples were ground into small particles using a $2 \mathrm{~mm}$ screen in a Model ED-5 Wiley Mill (Thomas Scientific, Swedesboro, NJ).

After grinding, samples were compression molded using a Model 3889 Hot Press (Carver Inc., Wabash, IN). Samples (30 g) were molded in a $3.5^{\prime \prime}$ by $3.5^{\prime \prime}$ window mold ( $1.8 \mathrm{~mm}$ thickness) at $140^{\circ} \mathrm{C}$ and 7500 lbs force (5000 lbs for $100 \%$ PCL) for $45 \mathrm{~min}$, then cooled for $15 \mathrm{~min}$ to $25^{\circ} \mathrm{C}$, and removed from the mold. After molding, samples were either cut into dumbbell-shaped tensile bars for testing or ground into powder for thermal analysis.

\section{Methods \\ Differential scanning calorimetry}

DSC measurements were carried out using a Q2000 MDSC $^{\mathrm{TM}}$ (TA Instruments, New Castle, DE). At first, composites were ground into powder using a Brinkmann/Retsch high-speed shaker mill. Powdered sample $(\sim 50 \mathrm{mg})$ was loaded and sealed in stainless steel high-volume pan and cooled to $-90^{\circ} \mathrm{C}$, equilibrated for $1.0 \mathrm{~min}$ in the DSC at $-90^{\circ} \mathrm{C}$ after which the temperature has increased to $150^{\circ} \mathrm{C}$ at $5^{\circ} \mathrm{C} / \mathrm{min}$ under modulation $\left( \pm 1^{\circ} \mathrm{C}\right.$ every $\left.60 \mathrm{~s}\right)$. All runs were done in duplicate.

\section{Thermogravimetric analysis}

TGA was performed using a 2050 TGA (TA Instruments, New Castle, DE). Samples $(\sim 10 \mathrm{mg}$ powder in duplicate) were heated from room temperature to $800^{\circ} \mathrm{C}$ at $10^{\circ} \mathrm{C} / \mathrm{min}$ and held at an isotherm for $3 \mathrm{~min}$. The TGA data were plotted as temperature vs. weight \% from which onset and final decomposition temperatures were obtained. Hereafter, these plots will be referred to as TGA plots. The TGA data were also plotted as temperature vs. derivative of weight $\%$ from which the peak decomposition temperatures were obtained (these plots will be referred to as DTGA plots.).

Additionally, from the TGA data, the degradationkinetics of neat PCL or composites was determined. According to Flynn and Wall, ${ }^{16}$ the activation energy of degradation $\left(E_{a}\right)$ was calculated using four heating rates $10,15,20$, and $25^{\circ} \mathrm{C} / \mathrm{min}$, based on the following eq. (1).

$$
\begin{aligned}
\log \beta \cong & 0.457\left(-\frac{E_{a}}{R T}\right) \\
& +\left[\log \left(\frac{A E_{a}}{R}\right)-\log F(a)-2.315\right]
\end{aligned}
$$

where $\beta$ is the heating rate, $T$ is the absolute temperature, $R$ is the gas constant, $a$ is the conversion, $E_{a}$ is the activation energy, and $A$ is the pre-exponential 
factor. According to this equation, $E_{a}$ can be obtained from the slope of $\log \beta$ versus $1000 / T$ (K) at the identical percent conversion. The $E_{a}$ calculation was done by the software provided by the manufacture (TA Advantage Specialty Library software, TA Instruments), where the $E_{a}$ value was determined for all samples at each heating rate and percent conversion. The $E_{a}$ was calculated according to Kissinger's method, as well, which is based on plotting the logarithm of heating rate versus the inverse of the temperature at the maximum of reaction rate in constant heating rate experiments. ${ }^{17}$

\section{Mechanical properties}

Mechanical property measurements were performed using a mechanical property testing machine (Model 4201, Instron Corporation, Norwood, MA) according to ASTM D638 Type IV fracture method. ${ }^{18}$ The thickness of individual tensile bars was measured before testing and ranged from 1.7 to $2.9 \mathrm{~mm}$. The gauge length was $7.62 \mathrm{~mm}$, and the strain rate was $10 \mathrm{~mm}$ / $\mathrm{min}$. All samples were conditioned for at least $48 \mathrm{~h}$ at standard room temperature and humidity $\left(23^{\circ} \mathrm{C}\right.$ and $50 \% \mathrm{RH})$. Each test was repeated at least five times and average values were used in data analysis.

\section{Fourier transform infrared spectroscopy}

Samples of gluten, PCL, their Brabender blended and compression-molded mixtures, and reaction products with MDI were prepared for FTIR spectroscopy. The granular samples were tested after drying under vacuum at $30^{\circ} \mathrm{C}$ for $24 \mathrm{hr}$ to eliminate water vapor. The liquid MDI was tested on $\mathrm{KBr}$ plates.

All granular samples were pressed into $\mathrm{KBr}$ powder to give disc-shaped pellets $(13 \mathrm{~mm} \times 1 \mathrm{~mm})$. Samples were frozen and pulverized cryogenically to minimize the particle and preserve the secondary molecular structures of the polymers. Cryogenic pulverization in liquid nitrogen also minimized absorption of atmospheric water vapor by $\mathrm{KBr}$ which prevented interference from water bands in the amide I and ester regions in gluten, PCL, and product spectra.

A sample $(1 \mathrm{mg})$ was mixed with $\mathrm{KBr}(300 \mathrm{mg})$ at liquid nitrogen temperature for $10 \mathrm{~s}$ on a Wig-L-Bug amalgamator (Crescent Dental Manufacturing, Lyons, IL). The mixture was transferred to a $\mathrm{KBr}$ die (Perkin-Elmer Corp. Norwalk, CT) and pressed under vacuum at $110 \mathrm{MPa}$ on a laboratory press (Fred S. Carver, Menominee Falls, WI) to form a transparent pellet.

Infrared spectra were measured on a Bomem MBSeries FTIR spectrometer (ABB, Houston, TX) equipped with a DTGS detector. The absorbance spectrum $\left(4000 \mathrm{~cm}^{-1}-400 \mathrm{~cm}^{-1}\right)$ for each sample was acquired at $4 \mathrm{~cm}^{-1}$ resolution and signal averaged over 32 scans.

\section{EXPERIMENTAL DESIGN AND STATISTICAL ANALYSIS}

A general linear model experimental design study of the effects of varying percentages of flour and gluten with constant $2 \%$ MDI on 2 processes (Blended and Comp mold) was utilized. Mean values of 2 replications of physical properties $\left(\%\right.$ Residue, Onset $1^{\circ} \mathrm{C}$, Peak $1^{\circ} \mathrm{C}$, Peak-1 percent-weight, Onset $2^{\circ} \mathrm{C}$, Peak $2^{\circ} \mathrm{C}$, and Peak-2 percent-weight) were obtained. A weighted means regression analysis for each process was conducted to obtain equations of mean physical property values as a function of gluten and flour percentage. Standard weights of 1 /variance were used for weighting the mean physical property values.

Full and reduced models were used to determine if there were significant differences between the 2 process equations for each physical property. If results showed significant differences between the equations, 95\% confidence intervals on the regression coefficients were used to check for equality of slopes and intercepts. If results showed no significant differences between the equations, the reduced model combining data for both processes into one master equation was obtained. Analyses were performed using SAS PC Windows Version 9.2 software. ${ }^{19}$

\section{RESULTS AND DISCUSSION}

\section{Mechanical properties}

The addition of MDI to PCL did not have significant impact on the tensile strength of $100 \%$ PCL or 70 : 30 PCL : flour/gluten blends. Noting deviations, there appears to be a slightly significant result of PCL-MDI-gluten being slightly stronger than PCLgluten without MDI. Tensile strength decreases for both gluten and flour until $30 \%$ fill when there is a slight increase of tensile strength indicating some reinforcement of the PCL polymer matrix by adhesion between the two phases. Wang et al. ${ }^{20}$ showed that MDI did provide compatibilization between PLA and wheat starch. The tensile strength of PLA was measured at $62 \mathrm{MPa}$ and $36 \mathrm{MPa}$ for PLA with $45 \%$ starch incorporated. With the addition of $2 \%$ MDI, the tensile strength was $65 \mathrm{MPa}$. Choi et al. ${ }^{21}$ showed that PCL loses its tensile strength with increasing amounts (up to $40 \% \mathrm{w} / \mathrm{w}$ ) of soy protein isolate. This study focused on the effects of coconut oil or poly (ethylene glycol) as a plasticizer. Zhong and $\operatorname{Sun}^{22}$ examined the effect of adding PCL to soy protein isolate, the dominant polymer phase 

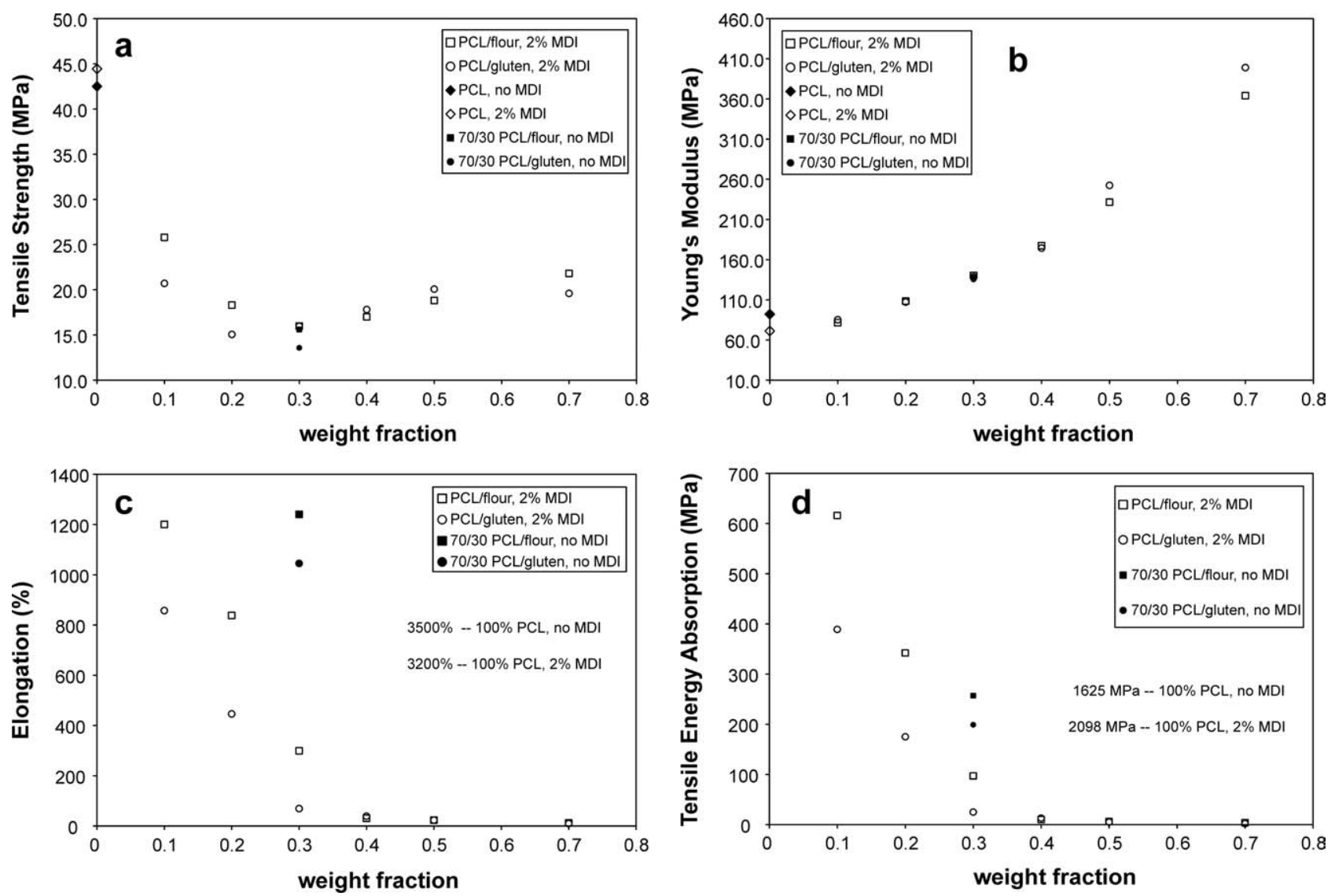

Figure 1 (a) Tensile strength of PCL-MDI-gluten/flour composite materials, (b) Young's modulus of PCL-MDI-gluten/ flour composite materials, (c) elongation of PCL-MDI-gluten/flour composite materials, and (d) tensile energy absorption of PCL-MDI-gluten/flour composite materials.

(50-100\% SPI) and determined that 2\% MDI gave the most reinforcement as defined by tensile strength. At 50\% PCL with 2\% MDI, Zhong and Sun 22 reported the tensile strength as $24 \mathrm{MPa}$, and ours for PCL-gluten was $20.1 \mathrm{MPa}$. They used different sample geometry and pull rate at $5 \mathrm{~mm} / \mathrm{min}$, making direct comparison difficult.

Young's Modulus increases with increasing fill rate as expected when filling a soft polymer with a hard filler. There is no difference in values until $70 \%$ fill where PCL-MDI-gluten has a higher modulus than PCL-MDI-flour. Gluten, the protein component, presumably has a higher elastic modulus than flour which is a combination of starch and protein. Zhong and Sun $^{22}$ used different sample geometry (Type IV tensile specimen) and pull rate $(5 \mathrm{~mm} /$ min), making direct comparison impossible. They reported a modulus of $650 \mathrm{MPa}$ for a 50/50 blend with $2 \%$ MDI. Our value for PCL-gluten is around $250 \mathrm{MPa}$. The modulus for 50/50 PCL-gluten and PCL-flour with $2 \%$ MDI was 252 and $231 \mathrm{MPa}$, respectively. $\mathrm{Yu}$ et $\mathrm{al}^{23}$ showed that the modulus of PCL-high amylose corn starch blends (no MDI) increased with increasing starch fill up to $30 \%$ ( $~ 430 \mathrm{MPa})$ and then decreased to $216 \mathrm{MPa}$ at $50 \%$ fill. In this study, the corn starch was plasticized with $30 \%$ water. As thermoplastic starch was incorporated into PCL at higher levels, the overall stiffness of the blend is expected to be reduced. The modulus for $100 \%$ PCL was $390 \mathrm{MPa}$. Yu et al. ${ }^{23}$ also showed the effect of MDI on modulus for PCLstarch was dependent on whether MDI was incorporated into the PCL phase or the starch phase before compounding. The modulus 50 : 50 PCL : starch (no MDI) was $216 \mathrm{MPa}$. For $1 \mathrm{w} / \mathrm{w} \%$ MDI added to the PCL-starch blend, the modulus was $\sim 290 \mathrm{MPa}$. For MDI blended with starch, the modulus was $\sim 225 \mathrm{MPa}$. MDI may be interacting predominantly with the hydroxyl groups of the water rather than the starch. For MDI blended with PCL, the modulus was $\sim 375 \mathrm{MPa}$ indicating that the MDI was interacting with and restricting the movement of the PCL chains.

Adding MDI to PCL resulted in a 9\% loss of elongation [see inset Fig. 1(c)]. The addition of $10 \%$ wheat flour or wheat gluten to PCL-MDI (2\%) resulted in a loss of $62 \%$ and $73 \%$ elongation from PCL-MDI alone. At $30 \%$ fill with MDI, the elongation values are $300 \%$ and $70 \%$ for flour and gluten respectively; corresponding values for no MDI 

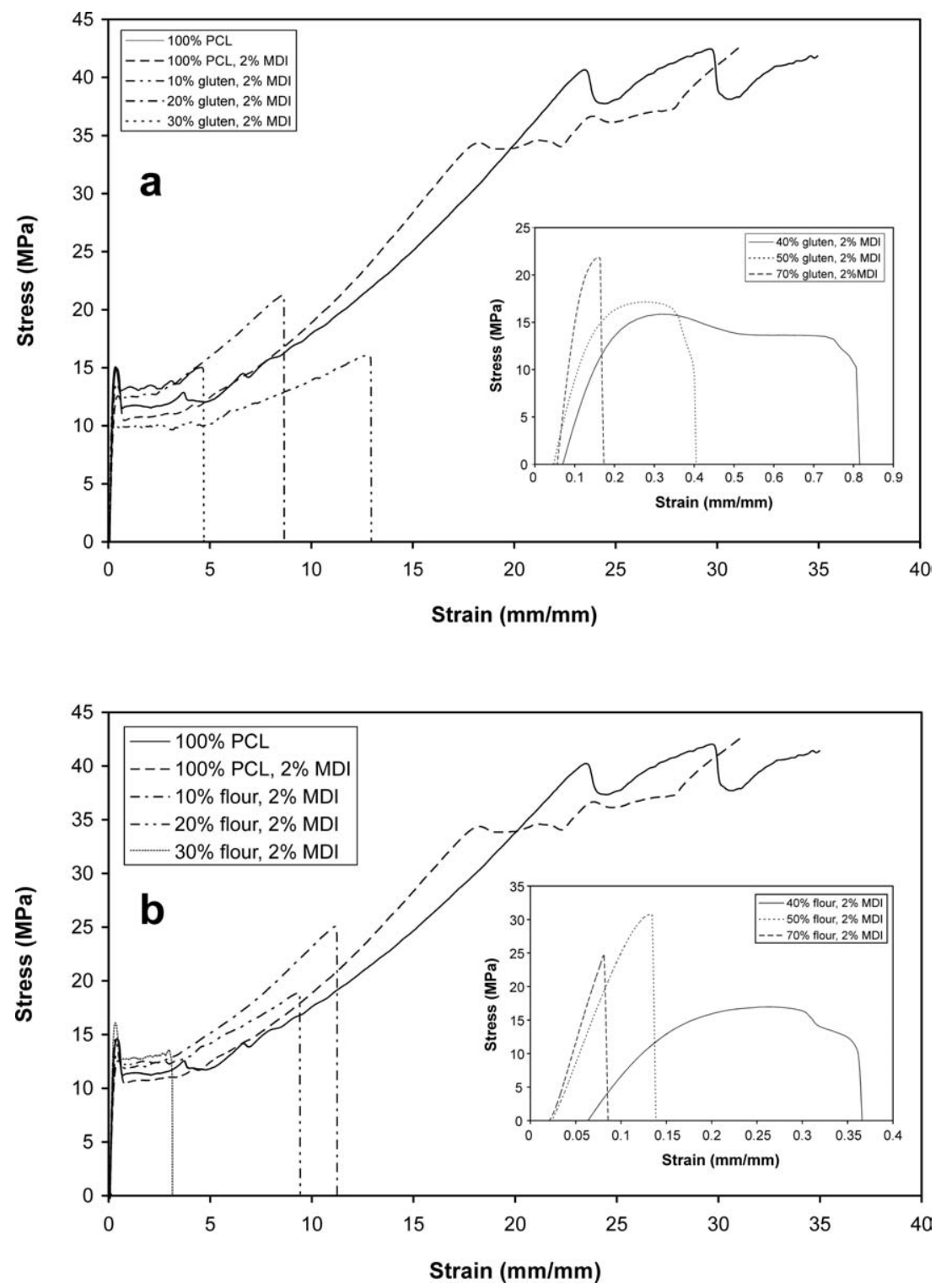

Figure 2 (a) Stress-strain curves for PCL-MDI composites filled with (a) flour and (b) gluten and (b) Stress-strain curves for PCL-MDI composites filled with (a) flour and (b) gluten.

addition are $1240 \%$ and $1045 \%$. PCL-flour loses $75 \%$ of its elongation and PCL-gluten loses $94 \%$ with the addition of MDI. The MDI favors interaction with the filler phase rather than the PCL phase (drop in elongation), and does not appear to react with both phases or one would expect the tensile strength to be affected on a greater scale.

Reduction in energy absorption (calculated as the area under the stress-strain curve) followed a linear decline as filler content increased [Fig. $2(a, b)]$. With $100 \%$ PCL, the addition of MDI increased total energy absorption [see inset Fig. 1(d)]. However, at $30 \%$ fill, the energy absorption decreases with MDI addition for both gluten and flour. This indicates that MDI preferentially interacts with the filler phase over PCL. Zhong and Sun ${ }^{22}$ indicated that a phase inversion occurred at 50\% PCL where the PCL became the dominant factor in the tensile properties as far as elongation and tensile energy absorption was concerned. We did not see any indication of phase inversion as the filler content went above $50 \%$ to $70 \%$ although there was a slight gain in tensile strength [Fig. 1(a)] above 30\% fill which is interpreted to be the MDI interaction rather than intrinsically part of the wheat gluten or flour property.

PCL-MDI composites yield in the first few seconds of strain and then show strain hardening with gluten or flour content up to $30 \%$ [Fig. $2(\mathrm{a}, \mathrm{b})]$. Yu et al. $^{23}$ had similar yield values for PCL loaded with starch and MDI. At 70\% fill, the gluten/flour becomes the dominant phase and is very brittle. Zhong and $\mathrm{Sun}^{22}$ showed that PCL-soy protein isolate $(50 / 50)$ with $2 \%$ MDI exhibits ductile behavior 
TABLE I

Weighted Regression Equations of Mean Physical Property Values

\begin{tabular}{|c|c|c|c|}
\hline Physical property & Process & Equation & Adj. $R^{2}$ \\
\hline \multirow[t]{2}{*}{$\%$ Residue $^{\mathrm{b}}$} & Blended & $\mathrm{Y}=0.0201+0.0018^{*} \mathrm{G}+0.0016^{*} \mathrm{~F}$ & $0.995^{\mathrm{a}}$ \\
\hline & Comp mold & $\mathrm{Y}=0.0167+0.0012^{*} \mathrm{G}+0.0015^{*} \mathrm{~F}$ & $0.965^{\mathrm{a}}$ \\
\hline \multirow[t]{3}{*}{ Onset ${ }^{\circ} \mathrm{C}$ First peak } & Blended & $\mathrm{Y}=246.2-147.8 / \operatorname{Ln}(\mathrm{G})-119.1 / \operatorname{Ln}(\mathrm{F})$ & $0.938^{\mathrm{a}}$ \\
\hline & Comp mold & $\mathrm{Y}=246.8-154.7 / \operatorname{Ln}(\mathrm{G})-131.6 / \operatorname{Ln}(\mathrm{F})$ & $0.983^{\mathrm{a}}$ \\
\hline & Master Eqn & $\mathrm{Y}=247-153.2 / \operatorname{Ln}(\mathrm{G})-129.6 / \operatorname{Ln}(\mathrm{F})$ & $0.980^{\mathrm{a}}$ \\
\hline \multirow[t]{2}{*}{ Peak ${ }^{\circ} \mathrm{C}^{\mathrm{b}}$ First peak } & Blended & $\mathrm{Y}=331.1-18.5^{*} \operatorname{Ln}(\mathrm{G})-15.2^{*} \operatorname{Ln}(\mathrm{F})$ & $0.994^{\mathrm{a}}$ \\
\hline & Comp mold & $\mathrm{Y}=326-19.4^{*} \operatorname{Ln}(\mathrm{G})-17.3^{*} \operatorname{Ln}(\mathrm{F})$ & $0.986^{\mathrm{a}}$ \\
\hline \multirow[t]{3}{*}{$\%$ Weight first Peak } & Blended & $\mathrm{Y}=0.041-1.197 / \operatorname{Ln}(\mathrm{G})-1.129 / \operatorname{Ln}(\mathrm{F})$ & $0.978^{\mathrm{a}}$ \\
\hline & Comp mold & $\mathrm{Y}=0.031-1.21 / \operatorname{Ln}(\mathrm{G})-1.124 / \operatorname{Ln}(\mathrm{F})$ & $0.944^{\mathrm{a}}$ \\
\hline & Master Eqn & $\mathrm{Y}=0.034-1.209 / \operatorname{Ln}(\mathrm{G})-1.126 / \operatorname{Ln}(\mathrm{F})$ & $0.972^{\mathrm{a}}$ \\
\hline \multirow[t]{3}{*}{ Onset ${ }^{\circ} \mathrm{C}$ Second peak } & Blended & $\mathrm{Y}=371.4-0.0029^{*} \mathrm{G}^{2}-\left(1.609 * 10^{-5}\right)^{*} \mathrm{~F}^{3}$ & $0.950^{\mathrm{a}}$ \\
\hline & Comp mold & $\mathrm{Y}=371.7-0.0024^{*} \mathrm{G}^{2}-\left(1.482^{*} 10^{-5}\right)^{*} \mathrm{~F}^{3}$ & $0.819^{\mathrm{a}}$ \\
\hline & Master Eqn & $\mathrm{Y}=371.4-0.0028^{*} \mathrm{G}^{2}-\left(1.604^{*} 10^{-5}\right)^{*} \mathrm{~F}^{3}$ & $0.920^{\mathrm{a}}$ \\
\hline \multirow[t]{3}{*}{ Peak ${ }^{\circ} \mathrm{C}$ Second peak } & Blended & $\mathrm{Y}=408.7-0.001 * \mathrm{G}^{2}-0.0098^{*} \mathrm{~F}^{1.5}$ & $0.944^{\mathrm{a}}$ \\
\hline & Comp mold & $\mathrm{Y}=409-0.0011^{*} \mathrm{G}^{2}-0.0109^{*} \mathrm{~F}^{1.5}$ & $0.994^{\mathrm{a}}$ \\
\hline & Master Eqn & $\mathrm{Y}=408.9-0.0011^{*} \mathrm{G}^{2}-0.0107^{*} \mathrm{~F}^{1.5}$ & $0.987^{\mathrm{a}}$ \\
\hline \multirow[t]{3}{*}{$\%$ weight second Peak } & Blended & $\mathrm{Y}=0.9855-0.0078^{*} \mathrm{G}-0.009^{*} \mathrm{~F}$ & $0.994^{\mathrm{a}}$ \\
\hline & Comp mold & $\mathrm{Y}=0.9832-0.0076^{*} \mathrm{G}-0.0088^{*} \mathrm{~F}$ & $0.995^{\mathrm{a}}$ \\
\hline & Master Eqn & $\mathrm{Y}=0.9864-0.0078^{*} \mathrm{G}-0.009^{*} \mathrm{~F}$ & $0.996^{\mathrm{a}}$ \\
\hline
\end{tabular}

Where $\mathrm{Y}=$ Mean physical property value, $\mathrm{G}=\%$ gluten, and $\mathrm{F}=\%$ flour.

${ }^{a}$ Indicates significant relationship between mean physical property and \% gluten and flour variables at $P<0.0001$.

$\mathrm{b}$ The process equations within each physical property are statistically different based on full and reduced model for $F$-tests at $P<0.05$.

which is more pronounced for wheat gluten or flour in PCL.

\section{Thermogravimetric analysis}

Although pMDI composed of 45-55\% pMDI, 35-45\% MDI, and $1-10 \%$ mixed isomers of MDI, its TGA degradation profile exhibited two major degradation peaks and a minor one. The first peak reached the highest point at $248^{\circ} \mathrm{C}(52.1 \% \mathrm{pMDI})$, the second at $321^{\circ} \mathrm{C}(17 \% \mathrm{MDI})$, the third at $515.5^{\circ} \mathrm{C}(7.5 \%$ mixed isomers), and $22.5 \%$ remaining residue. The minor peak appeared to have interacted with the composite components because the maximum peak-temperature of all composites $\left(460^{\circ} \mathrm{C}\right)$ was much lower than that of the mixed isomers $\left(515.5^{\circ} \mathrm{C}\right)$. The PCL profile showed one peak at $409.5^{\circ} \mathrm{C}$ and $<1 \%$ residue. The degradation profile of neat PCL showed a sharp drop in weight starting at $386.2^{\circ} \mathrm{C}$, whereas neat gluten exhibited a gradual drop in weight starting at $272.5^{\circ} \mathrm{C}$. Gluten degradation stopped at $20.7 \%$ residue (ashes) versus less than $1 \%$ for neat PCL. The weight loss profile of all composites, regardless of composition, was gradual where the onset of degradation was significantly influenced by the amount of gluten added. The presence of pMDI had no effect on the neat PCL degradation, whereas gluten-pMDI profile exhibited lower weight loss at the same temperature. The role of pMDI was more apparent in the profile of blended composites, as opposed to compression-molded, where a $70: 30$ (PCL : gluten) started degrading at a significantly higher temperature compared to the 70 : 30 without pMDI. The effect of pMDI on the compression molded samples was less obvious.

Regression equations were developed for predicting the effect of different gluten or flour levels on PCL degradation parameters such as onset or peak degradation temperatures and remaining residue (Table I). The equations were then used to determine if any parameter was significantly different within the blended samples or between compression molded (Table I). The Gluten beta coefficient (slope) for the Compression-mold process was significantly lower than for the Brabender-blended process as determined by nonoverlap of the $95 \%$ confidence intervals on the regression coefficients. The intercepts and slopes for flour were not different. Eventhough the full and reduced model F-tests showed significant differences between the equations for blended and compression-molded processes, the $95 \%$ confidence intervals on the regression coefficients showed no differences between the intercepts or slopes for gluten and flour between the two processes (Table I).

\section{Degradation kinetics}

The degradation kinetics obtained by analyzing TGA data according to Flynn Wall equation, where the 


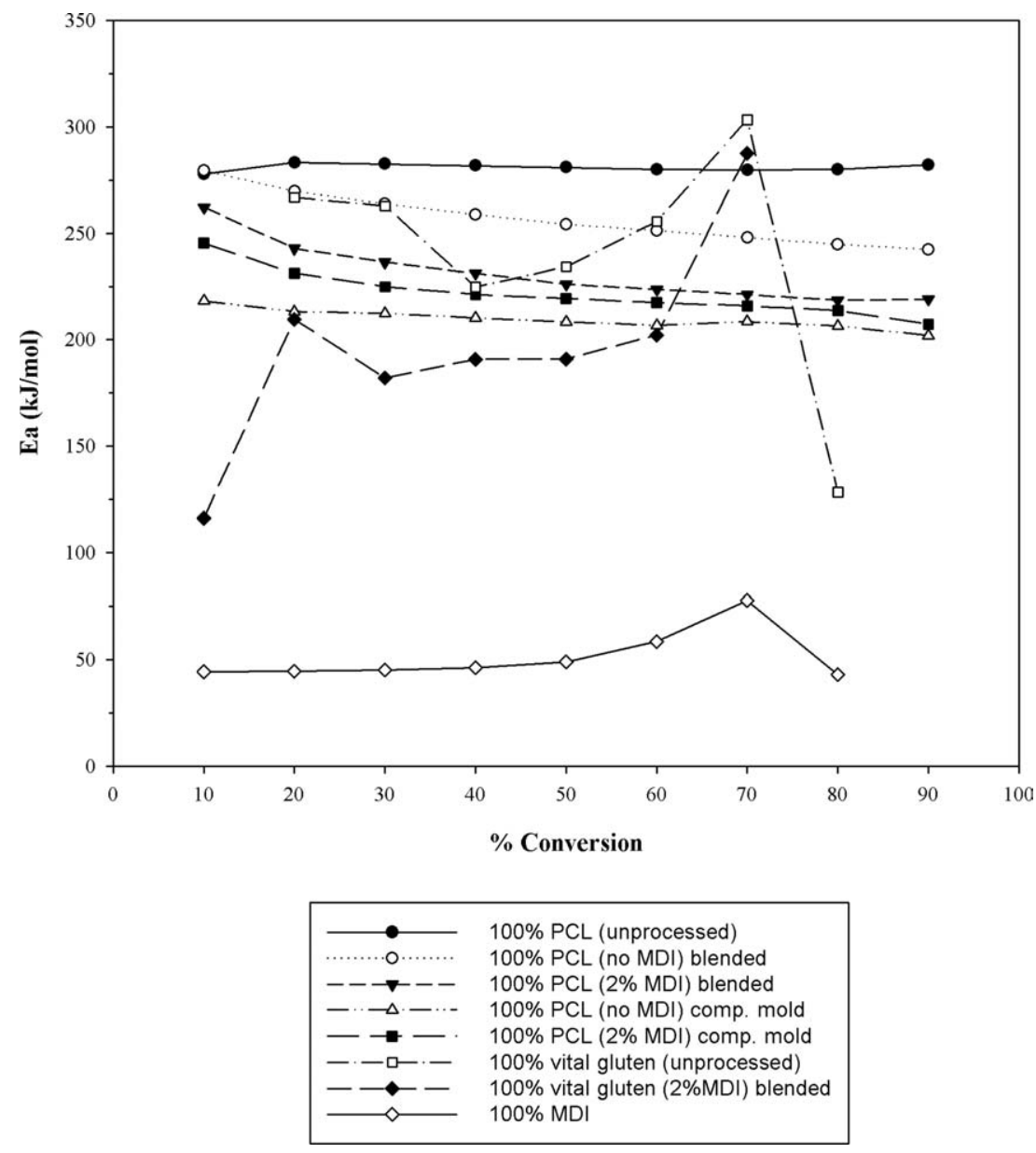

Figure 3 Decomposition kinetics profile of PCL and vital gluten.

full derivation of eq. (1) was reported in a previous publication. ${ }^{15,16}$ Heat degradation-mechanism of the neat polymers and the composites can be obtained by plotting the percent degradation-conversion (TGA analysis) versus activation energy $\left(E_{a}\right)$ (Figs. 3 and 4). The straight line, resulting from steady increase on the $E_{a}$ as the percent conversion increased, signifies one-step degradation, while variations on $E_{a}$ as a function of percent conversion, indicate a multistep process. The data presented in Figures 3 and 4 represent the neat polymers $(100 \%$ PCL or gluten) and the composites, respectively. The degradation mechanism curve for neat pMDI showed one step for all conversion levels except for 60 and $70 \%$ conversions where higher $E_{a}$ values indicates different mechanism (Fig. 3). This was expected due to the diverse composition of pMDI as mentioned in the material and method section (mostly PMDI and MDI). One can expect the part from $10 \%$ conversion to $50 \%$ to represent the pMDI and the other fractions correspond to MDI. Although neat VG was degraded in multiple steps, the addition of $2 \%$ pMDI decreased the $E_{a}$ in addition to the multisteps (Fig. 3). Blending and pMDI slightly reduced $E_{a}$ but did not change the degradation mechanism of neat unprocessed PCL (Fig. 3). The compression molded of neat PCL showed exact behavior as the blended, where as the addition pMDI increased $E_{a}$ gradually indicating multistep degradation mechanism at the early conversion steps. As mentioned in the mechanical properties section, pMDI seemed to interact with the filler (VG) rather than with PCL because its effect on VG degradation-mechanism was much more pronounced than with PCL (Fig. 3).

Neither TGA nor DSC is the best method to ascertain the nature of interaction between the components of composites, but these methods are good indicators of interaction. The degradation mechanism of the blended PCL/gluten composites exhibited more multisteps than the compression molded [Fig. $4(\mathrm{a}, \mathrm{b})]$. The blended $90: 10$ (PCL : gluten) composite showed a very different mechanism compared to the $100 \% \mathrm{PCL}$, where the profile indicates a two steps mechanism rather than one step for the $100 \%$ PCL as shown in Figure 3. Compression-molding appeared to have significant effect on the mechanism due to the drop in $E_{a}$ as a function of percent 

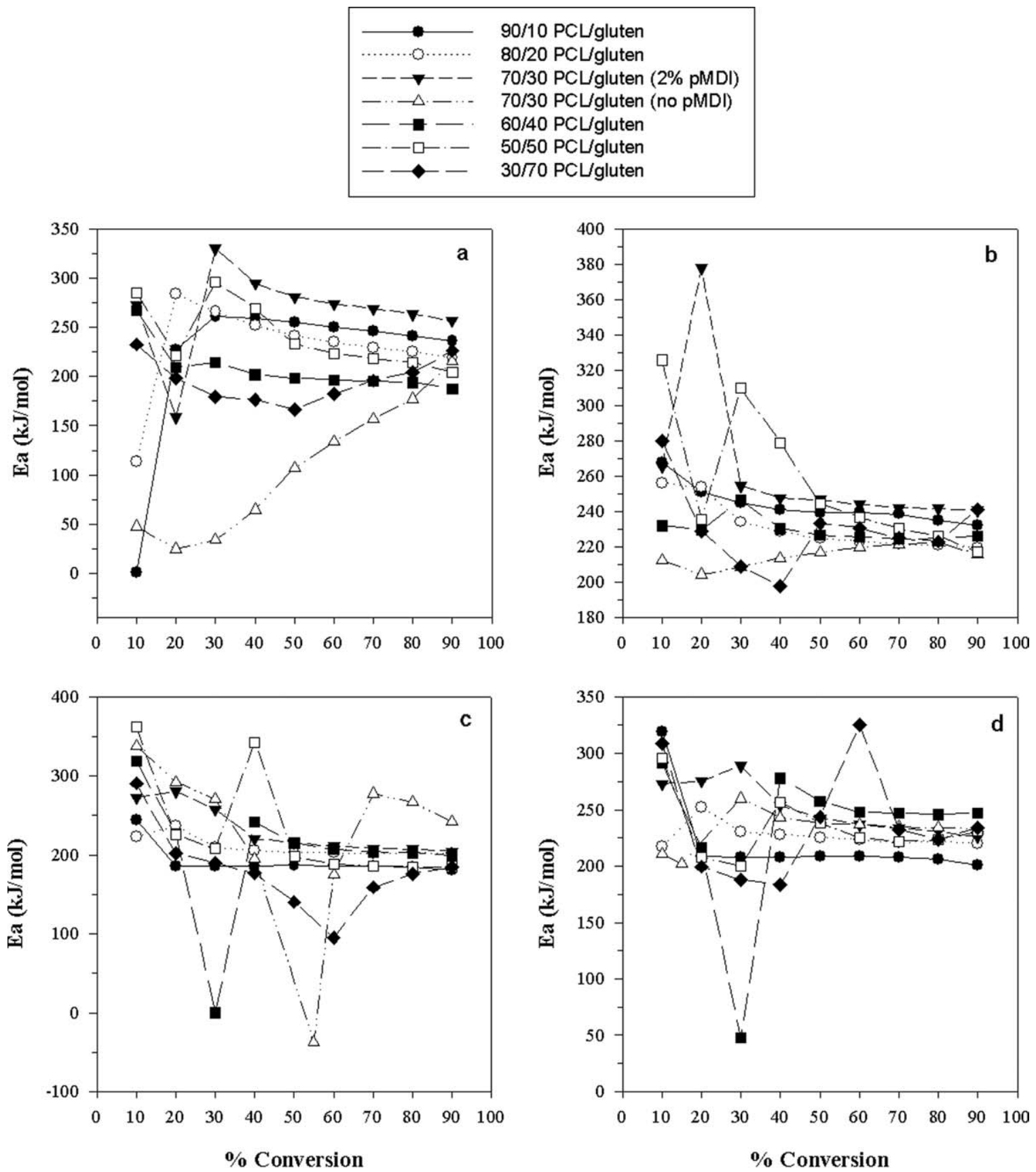

\begin{tabular}{|c|c|}
\hline & $\begin{array}{l}\text { 90/10 PCL/gluten } \\
\text { 80/20 } \mathrm{PCL} / \text { gluten }\end{array}$ \\
\hline$--\rightarrow--$ & $70 / 30 \mathrm{PCL} /$ gluten (2\% pMDI) \\
\hline$-\cdots-\Delta \cdot-\cdots$ & 70/30 PCL/gluten (no pMDI) \\
\hline$-\rightarrow-$ & $60 / 40 \mathrm{PCL} /$ gluten \\
\hline- - & 50/50 PCL/gluten \\
\hline$-\longrightarrow-$ & 30/70 PCL/gluten \\
\hline
\end{tabular}

Figure 4 Decomposition kinetics profile; (a) blended PCL/gluten; (b) Compression-molded PCL/gluten; (c) blended PCL/flour; (d) compression-molded PCL/flour.

conversion whereas the blended exhibited increase in $E_{a}$ [Fig. $4(\mathrm{a}, \mathrm{b})$ ]. The $50: 50$ composite showed the most degradation steps of all other gluten or flour composites. In the presence of flour, similar degra- dation behavior was observed, where the compression-molded 90 : 10 composite remained different from the others and was the most affected by compression molding [Fig. $4(\mathrm{c}, \mathrm{d})]$. Flour $(72 \%$ starch 
TABLE II

Summary of Differential Scanning Calorimetry Analysis of PCL/Vital Gluten/Flour Composites with 2\% pMDI

\begin{tabular}{llcccccccc}
\hline & & PCL & $30 / 70$ & $50 / 50$ & $60 / 40$ & $70 / 30$ & $80 / 20$ & $90 / 10$ \\
\hline $\mathrm{BL}^{\mathrm{a}}$ & $T_{g}\left({ }^{\circ} \mathrm{C}\right)^{\mathrm{c}}$ & -67.5 & - & - & -65.3 & -65.4 & -64.8 & -64.8 \\
& $\Delta C_{p}{ }^{\mathrm{d}}$ & 0.20 & - & - & 0.081 & 0.110 & 0.104 & 0.105 \\
$\mathrm{CM}^{\mathrm{b}}$ & $T_{g}\left({ }^{\circ} \mathrm{C}\right)$ & -67.6 & - & - & - & -64.9 & -64.9 & -66.5 & 0.45 \\
& $\Delta C_{p}$ & 0.17 & - & - & - & 0.085 & 0.105 & 0.174 & 0.40 \\
$\mathrm{BL}^{\mathrm{a}}$ & & $\mathrm{PCL}$ & $30 / 70$ & $50 / 50$ & $60 / 40$ & $70 / 30$ & $80 / 20$ & $90 / 10$ & $\mathrm{FL}^{\mathrm{f}}$ \\
& $T_{g}\left({ }^{\circ} \mathrm{C}\right)$ & -67.5 & - & - & - & -65.7 & -64.9 & -64.5 & - \\
& $\Delta C_{p}{ }^{\mathrm{d}}$ & 0.20 & - & - & - & 0.085 & 0.085 & 0.092 & - \\
$\mathrm{CM}^{\mathrm{b}}$ & $T_{g}\left({ }^{\circ} \mathrm{C}\right)$ & -67.6 & - & - & - & -65.2 & -64.4 & -64.4 & - \\
& $\Delta C_{p}$ & 0.17 & - & - & - & 0.083 & 0.107 & 0.110 & - \\
\hline
\end{tabular}

${ }^{\mathrm{a}} \mathrm{BL}=$ blended.

${ }^{\mathrm{b}} \mathrm{CM}=$ compression molded.

${ }^{\mathrm{c}} \mathrm{Tg}{ }^{\circ} \mathrm{C}=$ glass transition.

${ }^{\mathrm{d}} \Delta \mathrm{Cp}=$ in $\mathrm{J} / \mathrm{g} /{ }^{\circ} \mathrm{C}$.

${ }^{\text {e }} \mathrm{VG}=$ vital gluten .

${ }^{\mathrm{f}} \mathrm{FL}=$ flour.

and $16 \%$ protein) is expected to behave differently as was shown in the discussion of mechanical properties. The blended $70: 30$ composite behavior without pMDI was different from that with pMDI as shown in Figure $4(\mathrm{a}, \mathrm{b})$ indicating the effect of pMDI.

The data calculated by Kissinger method (Table III) for pure PCL showed slight $(3 \%)$ reduction on $E_{a}$ in the presence of pMDI for the blended sample, while a $12 \%$ increase on $E_{a}$ for the compression molded. The data calculated by Flyn-Walls showed similar trend (Table IV). The effect of compression molding on the $E_{a}$ values calculated by both methods was obvious. Overall, the $E_{a}$ values are higher with Flyn-Walls method compared to Kissinger method. The two methods gave different considerations regarding reaction order and mechanism, where Flyn-Walls did not consider reaction order and Kissinger did not consider reaction mechanism. The two approaches could be the cause of variation between the $E_{a}$ reported here, but both method showed similar trends as demonstrated in Table III and IV. It is evident in Table IV the increase in $E_{a}$ with increase in gluten in the composite. This phenomenon was true for PCL/gluten composites reported earlier (Mohamed et al., 2008).

\section{Differential scanning calorimetry}

Polymer binary-blend miscibility can estimated using DSC as follows: (a) immiscible-a blend that displays two glass transitions $\left(T_{g}\right)$ and two peak temperatures $\left(T_{m}\right)$; (b) miscible- $\mathrm{a}$ blend that displays composition-dependency indicated by a single $T_{g}$ and a single $T_{m}$ in the entire composition range;

TABLE III

Activation Energies of Blended and Compression Molded PCL with and Without pMDI Using the Kissinger Method

\begin{tabular}{cccccccc}
\hline \multirow{2}{c}{ Sample } & $\begin{array}{c}\text { Heating } \\
\text { rate }\end{array}$ & $T_{p}\left({ }^{\circ} \mathrm{C}\right)$ & $T_{p}(\mathrm{~K})$ & $1000 / T_{p}(\mathrm{~K})$ & $\beta / T_{p}{ }^{2}$ & $-\ln \left(\beta / T_{p}{ }^{2}\right)$ & $\begin{array}{c}E_{a} \\
(\mathrm{~kJ} / \mathrm{mol})\end{array}$ \\
\hline Blended PCL & 10 & 409.3 & 682.5 & 1.4653 & $2.15 \times 10^{-5}$ & 10.749 & 215.75 \\
(no MDI) & 15 & 415.8 & 689.0 & 1.4515 & $3.16 \times 10^{-5}$ & 10.362 & \\
& 20 & 421.2 & 694.4 & 1.4402 & $4.15 \times 10^{-5}$ & 10.090 & \\
Blended PCL & 25 & 425.2 & 698.4 & 1.4319 & $5.13 \times 10^{-5}$ & 09.879 & \\
(2\% MDI) & 10 & 409.0 & 682.2 & 1.4660 & $2.15 \times 10^{-5}$ & 10.748 & 206.66 \\
& 15 & 416.9 & 690.1 & 1.4492 & $3.15 \times 10^{-5}$ & 10.365 & \\
Comp. Mold PCL & 20 & 420.8 & 694.0 & 1.4410 & $4.15 \times 10^{-5}$ & 10.089 & \\
(no MDI) & 10 & 426.0 & 699.2 & 1.4303 & $5.11 \times 10^{-5}$ & 09.881 & \\
& 15 & 416.9 & 682.9 & 1.4645 & $2.14 \times 10^{-5}$ & 10.750 & 200.73 \\
Comp. Mold PCL & 20 & 421.3 & 694.1 & 1.4492 & $3.15 \times 10^{-5}$ & 10.365 & \\
(2\% MDI) & 10 & 427.2 & 700.4 & 1.4400 & $4.15 \times 10^{-5}$ & 10.091 & \\
& 15 & 415.9 & 684.1 & 1.4619 & $2.1 \times 10^{-5}$ & 09.884 & \\
& 20 & 419.6 & 699.1 & 1.4513 & $3.16 \times 10^{-5}$ & 10.753 & 225.79 \\
\hline
\end{tabular}


TABLE IV

Comparison of Activation Energies of PCL/Gluten Composites Calculated by Flyn-Walls and Kissinger Methods

\begin{tabular}{|c|c|c|c|}
\hline Sample & Process & Kissinger $E_{a}$ & $\begin{array}{c}\text { Flynn-Walls } \\
\text { Avg. } E_{a}\end{array}$ \\
\hline 100\% PCL (no MDI) & Blended & 215.75 & 256.97 \\
\hline 100\% PCL (2\% MDI) & & 206.66 & 231.28 \\
\hline 90/10 PCL/gluten & & 209.54 & 219.61 \\
\hline 80/20 PCL/gluten & & 216.07 & 229.33 \\
\hline 70/30 PCL/gluten (no MDI) & & 179.07 & 106.7 \\
\hline $70 / 30$ PCL/gluten (2\% MDI) & & 235.40 & 266.59 \\
\hline 60/40 PCL/gluten & & 189.52 & 207.14 \\
\hline 50/50 PCL/gluten & & 201.93 & 240.53 \\
\hline 30/70 PCL/gluten & & 199.11 & 195.71 \\
\hline 90/10 PCL/flour & & 197.55 & 191.68 \\
\hline 80/20 PCL/flour & & 175.48 & 209.52 \\
\hline 70/30 PCL/flour (no MDI) & & 185.94 & 224.16 \\
\hline 70/30 PCL/flour (2\% MDI) & & 204.40 & 230.77 \\
\hline 60/40 PCL/flour & & 181.96 & 201.66 \\
\hline 50/50 PCL/flour & & 202.84 & 230.98 \\
\hline 30/70 PCL/flour & & 222.55 & 179.19 \\
\hline 100\% PCL (no MDI) & Comp. Mold & 200.73 & 209.6 \\
\hline 100\% PCL (2\% MDI) & & 225.79 & 221.87 \\
\hline 90/10 PCL/gluten & & 223.99 & 243.18 \\
\hline 80/20 PCL/gluten & & 208.55 & 231.41 \\
\hline 70/30 PCL/gluten (no MDI) & & 214.60 & 214.98 \\
\hline $70 / 30 \mathrm{PCL} /$ gluten (2\% MDI) & & 229.52 & 262.28 \\
\hline 60/40 PCL/gluten & & 203 & 229.54 \\
\hline 50/50 PCL/gluten & & 216.77 & 256.11 \\
\hline 30/70 PCL/gluten & & 206.53 & 229.82 \\
\hline 90/10 PCL/flour & & 204.05 & 219.54 \\
\hline 80/20 PCL/flour & & 205.38 & 226.69 \\
\hline 70/30 PCL/flour (no MDI) & & 198.34 & 232.4 \\
\hline 70/30 PCL/flour (2\% MDI) & & 206.21 & 251.11 \\
\hline 60/40 PCL/flour & & 213.42 & 230.89 \\
\hline 50/50 PCL/flour & & 194.85 & 233.38 \\
\hline 30/70 PCL/flour & & 187.11 & 237.61 \\
\hline
\end{tabular}

(c) partially miscible-a blend that displays two $T_{g}$ and two $T_{m}$ that are composition dependent ${ }^{24}$ and / or composition-dependent single $T_{g}$ and single $T_{m}$ in a narrow composition range. The thermal history of PCL was erased by eliminating the first DSC cycle; while all data discussed below represent the second heating and cooling DSC cycles. Neat PCL cycle included a glass transition $\left(T_{g}\right)$, endothermic during heating (melting), and exothermic during cooling (crystallization) transitions (an example of DSC profile was shown in a previous publication ${ }^{15}$ ), whereas VG exhibited only glass transition $\left(T_{g}\right)$, and flour showed no transition. The corresponding glass transition $\left(T_{g}\right)$ temperature and the heat capacity $\left(\Delta C_{p}\right)$ for the neat polymers and composites are listed in Table II. The $T_{g}$ temperature of neat PCL (-67.5) was not affected by blending or compression molding, while $\Delta C_{p}$ dropped by $15 \%$ after compression molding (Table II). Gluten exhibited $T_{g}$ at $63^{\circ} \mathrm{C}$ and $0.45\left(\mathrm{~J} / \mathrm{g} /{ }^{\circ} \mathrm{C}\right)$, whereas flour showed no transition under conditions of this experiment, such as low moisture content. Although neat PCL or gluten exhibited a glass transition each, composites (PCL : gluten) showed one glass transition for the $90: 10$, $80: 20,70: 30,64: 40$, and no glass transition for the $50: 50$ and $30: 70$ composites. In addition, by examining the $T_{g}$ values of the composites, it is obvious that PCL glass transition values dominated those of the composites because the $T_{g}$ temperatures and $\Delta C_{p}$ were similar to those of the PCL (Table II). The presence of a single $T_{g}$ or no $T_{g}$ are indications of interactions. As mentioned above, pMDI appeared to interact with the gluten (filler) rather than with PCL, which could be the reason for the presence of the single $T_{g}$ around the $T_{g}$ of PCL, as PCL was not directly affected by pMDI. The behavior of PCL and gluten in this composite in the presence of PMDI was similar to that in its absence as reported in an earlier publication (Mohamed et al., 2008).

The peak temperature of the endothermic (melting/heating) transition of PCL with or without pMDI appeared at $60^{\circ} \mathrm{C}$, whereas the corresponding temperature during exothermic (crystallization/cooling) was $30^{\circ} \mathrm{C}$. The lower $\Delta H$ values of PCL in the 

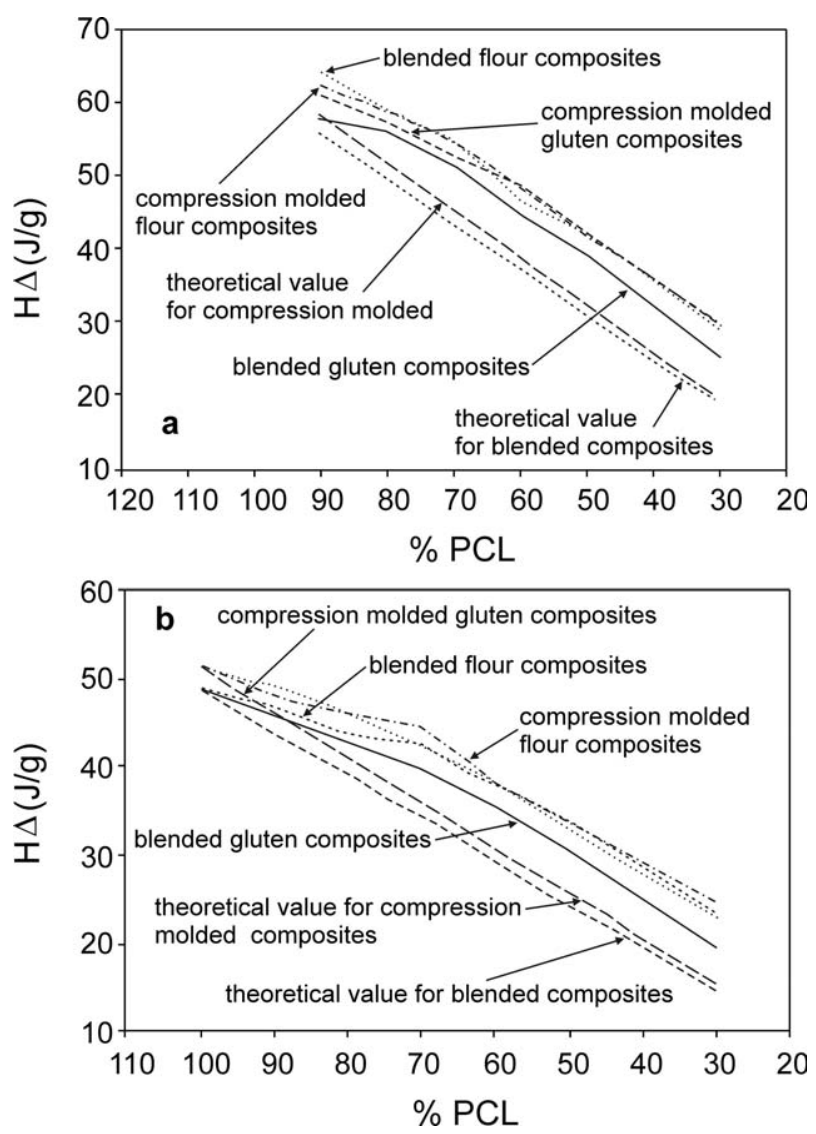

Figure 5 Effect of gluten and flour on the $\Delta H$ of neat PCL; (a) melting profiles; (b) crystallization profile.

presence of pMDI indicate some physical interaction, perhaps pMDI acted as spacer between PCL molecules thus reducing the $\Delta H$ and lowering the crystallization temperature. The composites exhibited higher $\Delta H$ compared to the theoretical value [Fig. 5 $(a, b)]$. The theoretical value was calculated based on the expected drop in $\Delta H$ value with the same percent drop in PCL in the composite, i.e., 90 : 10 contained $90 \%$ PCL and 10\% gluten; therefore, the drop in $\Delta H$ should be $10 \%$, theoretically. This comparison was made for all samples and shown in Figure 5 $(\mathrm{a}, \mathrm{b})$, where both melting and cooling $\Delta H$ values were higher than the theoretical values signifying some sort of interaction. Once again we observed change in the behavior of the $70: 30$ composites, where the $\Delta H$ values shifted [Fig. $5(\mathrm{a}, \mathrm{b})$ ].

\section{FTIR spectroscopy}

The FTIR spectra of PCL and gluten are shown overlaid in Figure 6(a). The spectrum of the reaction product of a $70: 30$ blend of PCL and gluten with $2 \%$ MDI is shown in Figure 6(b). PCL, which has the chemical structure shown in Figure 7 , produced a very strong carbonyl $(\mathrm{C}=\mathrm{O})$ peak at $1729 \mathrm{~cm}^{-1}$ and medium peaks between 2868 and $2949 \mathrm{~cm}^{-1}$ from methylene $\left(\mathrm{CH}_{2}\right)$ groups in PCL. As gluten is a protein, which comprises such amino acid sequences as the one represented by the tri-peptide structure of alanine, cysteine, and serine illustrated in Figure 7, its infrared spectrum shows a strong amide $\mathrm{I}(\mathrm{C}=\mathrm{O})$ peak at $1640 \mathrm{~cm}^{-1}$, a medium amide II $(\mathrm{NH})$ peak at $1550 \mathrm{~cm}^{-1}$, and broad hydroxyl $(\mathrm{OH})$ bands centered at $3315 \mathrm{~cm}^{-1}$ which are characteristic of proteins. The chemical structure of the major active pMDI component, methylene diphenyl 4,4'-diisocyanate (MDI), is also shown in Figure 7.

FTIR spectra of the unprocessed PCL, gluten, and HRS flour were compared with the Brabender blended and compression molded PCL-MDI-gluten and PCL-MDI-flour reaction mixtures. Spectra of the PCL-gluten and PCL-flour controls prepared as Brabender blended and compression molded mixtures without MDI were also compared. A spectrum of a sample of the Brabender PCL-gluten control that was spiked with MDI at $2 \%$ and kept cold (5$10^{\circ} \mathrm{C}$ ) to prevent the isocyanate reaction was used to estimate the extent of MDI disappearance in the heated reaction mixtures. When compared with this MDI spiked control the spectra of the heated PCLMDI-gluten and PCL-MDI-flour reaction mixtures showed more than $95 \%$ disappearance of the MDI.

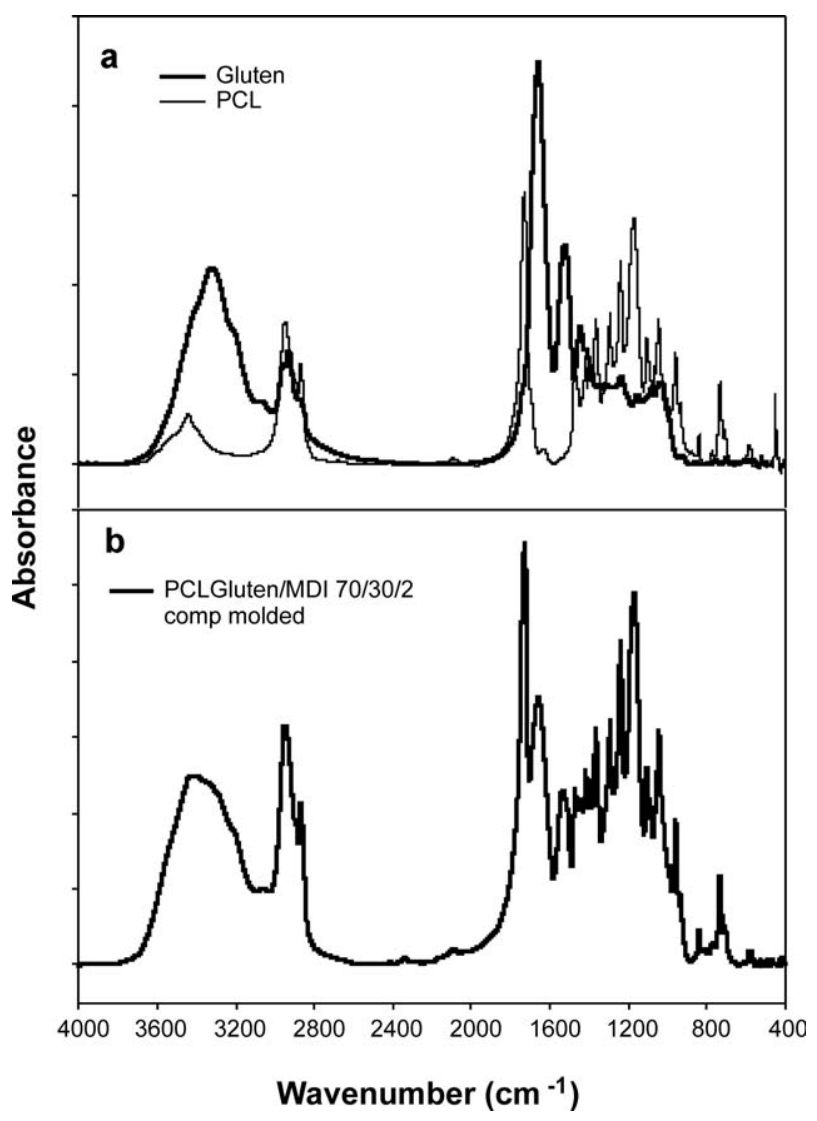

Figure 6 (a) FTIR spectra of unprocessed Gluten and polycaprolactone (PCL) and (b) FTIR spectrum of MDI reaction product of PCL with Gluten. 


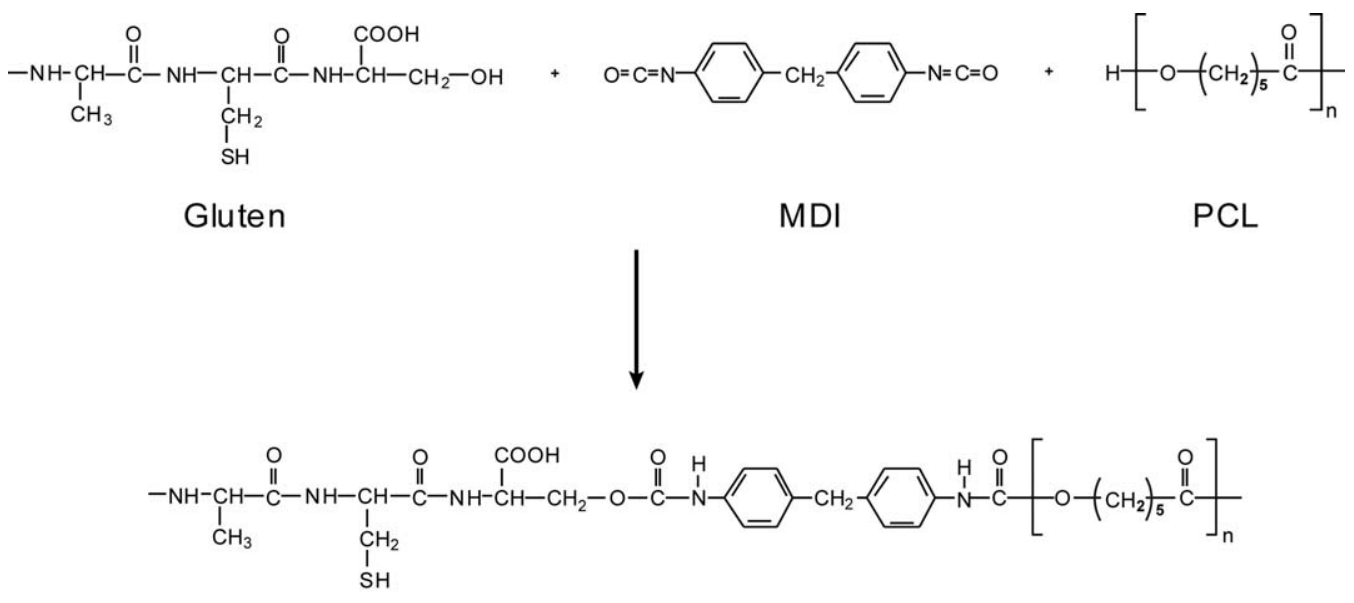

Polyurethane

Figure 7 Reaction of MDI with Gluten and PCL.

All of these FTIR spectra showed evidence of less than 5\% unreacted MDI.

However, none of the PCL-MDI-gluten and PCLMDI-flour reaction mixtures showed spectral evidence of the expected urethane crosslinks or other major chemical changes in the gluten, flour, or PCL during the reaction. It is presumed that urethane ( $\mathrm{R}-\mathrm{NH}-\mathrm{COOR})$ crosslink formation did actually occur in the mixtures as shown in Figure 7, but at the $2 \%$ MDI level, the amount of urethane formation was evidently too small to produce detectable infrared bands. Only very small isocyanate bands (2350 $\mathrm{cm}^{-1}$ ) remaining from traces of unreacted MDI were detectable in the spectra. Nevertheless, as samples of the PCL-pMDI-gluten and PCL-pMDI-flour reaction mixtures were more brittle than the PCL-gluten and PCL-flour controls (during cryogenic pulverization to produce $\mathrm{KBr}$ pellets), most of the brittleness very likely resulted from urethane crosslinks in the mixtures.

The pMDI reaction with secondary amine and carboxyl groups in gluten can also produce ureide $(\mathrm{R}-\mathrm{NH}-\mathrm{CO}-\mathrm{NR}-\mathrm{CO}-\mathrm{R})$ and urea $(\mathrm{R}-\mathrm{NH}-$ $\mathrm{CO}-\mathrm{NH}-\mathrm{R})$ crosslinks respectively in the gluten. ${ }^{25}$ Crosslinking through urethane, ureide, and urea groups would explain the increases in brittleness and tensile strength seen here as well as these same increases and the decreases in water absorption reported by Zhong and $\operatorname{Sun}^{22}$ for PCL-protein blends that were reacted with pMDI. It is well known that relatively small numbers of intermolecular crosslinks can produce large changes in physical properties of natural polymers and blends. ${ }^{26,27}$

Although it was found in earlier work ${ }^{28}$ that gluten was partially deaminated by heating at $190^{\circ} \mathrm{C}$ in a Brabender mixer, the lower heat $\left(120^{\circ} \mathrm{C}\right)$ and conditions of mixing and compression molding used in this work did not significantly deaminate the gluten or the flour. The FTIR spectra showed the amide I $\left(1640 \mathrm{~cm}^{-1}\right)$ and amide II $\left(1550 \mathrm{~cm}^{-1}\right)$ peaks from protein in the Brabender blended and compressionmolded mixtures were not noticeably decreased. Also, in comparing FTIR spectra of unprocessed PCL with PCL-gluten and PCL-flour controls, there was no evidence of chemical change in PCL caused by the reaction.

Close inspection of the position of the carbonyl peak in the PCL showed no evidence of noncovalent intermolecular interaction of PCL with gluten or flour in any of the processed mixtures, either the PCL-MDI-gluten and PCL-MDI-flour reaction mixtures or the PCL-gluten and PCL-flour controls. The position of the carbonyl peak $\left(1729 \mathrm{~cm}^{-1}\right)$ did not change in any of the mixtures after processing. Therefore, the FTIR spectra showed that the chemical structures of gluten, flour, and PCL were retained in Brabender blending and compression molding, and the composites evidently emerged as physical crosslinked mixtures with no measurable noncovalent intermolecular interaction. When compared to previous work done by our group (Mohamed et al., 2008), this work verified the physical nature of the interaction between the components in the composite as shown by FTIR. Although the presence of pMDI did not change the nature of the interaction, it is shown in this work that pMDI interacted mostly with the gluten rather than PCL.

\section{CONCLUSIONS}

Although the addition of pMDI had no significant impact of the tensile strength, the presence of pMDI provided re-enforcement in the interface between PCL and fillers. Young's Modulus increases with increasing fill rate, where elongation was reduced by 
9\% upon the addition of pMDI. PCL-MDI composites yield in the first few seconds of strain and then show strain hardening with gluten or flour content up to $30 \%$. The TGA analysis of the composites resembled the gluten degradation profile rather than the PCL. The degradation kinetics of neat polymers with $2 \%$ pMDI exhibited a multistep degradation mechanism as the percent conversion increased. Blending did not change the degradation mechanism of neat unprocessed PCL, but it reduced the $E_{a}$, while the addition of $2 \%$ pMDI before blending brought the $E_{a}$ closer to neat PCL. The degradation mechanism gave extra evidence for the more impact of pMDI on the filler than PCL. The DSC data showed the strongest evidence for interaction between PCL and the fillers, where one glass transition for the composites was emerged. Overall, FTIR analysis revealed strong possibility for physical noncovalent interaction between the blended and compression-molded components.

The authors thank Jason Adkins for conducting the MDSC and TGA experiments; Richard Haig, Kathy Hornback, Gary Grose, and Brian Jasberg for their help with the mechanical properties.

\section{References}

1. Jacob, J.; Jian, T.; Mrinal, B. Polymer 1998, 39, 2883.

2. Wang, Y.; Hillmyer, M. Proc Polym Mater: Sci Eng 2001, 85, 597.

3. Ljungberg, N.; Andersson, T.; Wesslen, B. J Appl Polym Sci $2003,88,3239$.

4. Ljungberg, N.; Wesslen, B. J Appl Polym Sci 2002, 86, 1227.
5. Ljungberg, N.; Wesslen, B. Polymer 2003, 44, 7679.

6. Soriano, I.; Evora, C. J Control Release 2000, 68, 121.

7. Shogren, R. L.; Willett, J. L. Annu Tech Conf Soc Plast Eng 2001; 59, 1860.

8. Willett, J. L.; Shogren, R. L. Polymer 2002, 43, 5935.

9. Li, J.; He, Y.; Inoue, Y. Polym Int 2003, 52, 949.

10. Mohamed, A.; Gordon, S. H. Proceedings NATAS Annual Conference Thermal Analysis Applications, Albuquerque, New Mexico, 2002; p 281.

11. Cai, Q.; Yang, J.; Bei, J.; Wang, S. Biomaterials 2002, 23, 4483.

12. Ouchi, T.; Kontani, T.; Ohya, Y. Polymer 2003, 44, 3927.

13. Zheng, S.; Guo, Q.; Mi, Y. Polymer 2003, 44, 867.

14. Mohamed, A.; Gordon, S. H.; Biresaw, G. Polym Degrad Stab 2007, 92, 1177.

15. Mohamed, A.; Finkenstadt, V. L.; Gordon, S. H.; Biresaw, G.; Palmquist, D. E.; Rayas-Duarte, P. J Appl Polym Sci 2008, 110, 3256.

16. Flynn, J. H.; Wall, L. A. Polym Lett 1966, 323.

17. Kissinger, H. E. Anal Chem 1957, 29, 1702.

18. ASTM D 638-91. Annual Book of ASTM Standards, Vol. 8.01; American Society for Testing and Materials: Philadelphia, 1992; 161.

19. SAS Institute Inc. SAS PC Windows Version 9.2; SAS Institute Inc.: Cary, NC, USA, 2002-2008.

20. Wang, H.; Sun, X.; Seib, P. J Appl Polym Sci 2001, 82, 1761.

21. Choi, W. Y.; Lee, C. M.; Park, H. J. LWT - Food Sci Technol 2006, 39, 591.

22. Zhong, Z.; Sun, X. S. Polymer 2001, 42, 6961.

23. Yu, L.; Dean, K.; Yuan, Q.; Chen, L.; Zhang, X. J Appl Polym Sci $2007,103,812$.

24. Archondouli, P. S.; Kallitsis, J. K.; Kalfoglou, N. K. J Appl Polym Sci 2003, 88, 612.

25. Gordon, S. H.; Doane, W. M. Carbohydr Res 1980, 79, 205.

26. Smith, H. E.; Gordon, S. H.; Russell, C. R.; Rist, C. E. Tappi 1970, 53, 1704.

27. Hamerstrand, G. E.; Smith, H. E.; Gordon, S. H.; Schulte, M. I.; Russell, C. R. Tappi 1977, 60, 131.

28. Mohamed, A.; Gordon, S. H.; Carriere, C. J.; Kim, S. J Food Qual 2006, 29, 266. 